\title{
The Effect of Scaffolding on the Vocabulary Improvement of EFL Iranian Language Learner
}

\author{
Seddigheh Jafari
}

\author{
MA degree in TEFL, Islamic Azad University, Bandar Abbas, Iran
}

\begin{abstract}
This study investigated the effectiveness of scaffolding on knowledge of the vocabularies of Iranian EFL language learners. The purpose of this study was to see whether scaffolding is effective for learners or not. The participants were 22 EFL students from Bandar Abbas.11 students were in control group and 11 students were in experimental group. The study was an experimental, preposttest control group design. Students were randomly assigned to form a treatment group and a control group. The results from the ANCOVA reveal that prior English oral vocabulary knowledge predicted student's success during the vocabulary scaffolding intervention, and scaffolding has positive effects on learning vocabulary. The current study has several practical and scientific implications. For instance, the scaffolding intervention program is useful for teacher education or professional development programs, as well as EFL learners.
\end{abstract}

Keywords-Scaffolding, Vocabulary, EFL.

\section{INTRODUCTION}

According to Van American state politico, Volman and Beishuizen (2010,p.274), staging refers to "support given by a lecturer to a student once activity a task that the coed would possibly otherwise not be able to accomplish." it's the temporary support given to students severally or together to complete a task they can't do while not steerage(Graves, Watts, \& Graves, 1994).Like physical staging, this support is incrementally removed once it's now not necessary, and therefore the teacher step by step shifts additional responsibility to the learners (Poorahmadi, 2009). What they're expected to grasp. The teacher would possibly use it to maneuver students' learning and understanding one leap forward or to scale back the negative emotions that students could expertise whereas trying to complete a difficult task without assistance. This study compares the effect of scaffolding on Iranian undergraduate EFL students' vocabulary retention at the individual and small group levels.

\subsection{Reading comprehension in an EFL context}

Weir (1993) discussed that reading could be seen as a discerning process between reader and text, involving the reader's background knowledge and a wide range of language knowledge in order to comprehend the text. In this case, readers activate their knowledge to predict and interpret the text they read, rather than reading all the words within the text. Therefore, the readers play an important role in constructing meaning related to the text.

Smith and Burns (2005) believe that reading is a complicated activity involving many variables related to reader, textual, and contextual aspects. In this sense, reading is not only a receptive activity to collect information, but also an interactive activity to interpret, analyze, and predict meaning from the text (Myers \& Palmer, 2002).

In an EFL reading activity, we may assume that comprehensible input from the text has a powerful effect on improving students' comprehension. In this sense, more comprehensible vocabulary in the text will make it easier to be comprehended by readers. However, what is comprehensible input for one reader may be partially or totally incomprehensible for others.

In line with the views just presented, the current study will consider and characterize reading comprehension as a dynamic productive activity process that aims to understand, predict, and interpret the meaning of the text in order to arrive at comprehension. The reader is an active participant who has a central role as an interpreter of the text. Reading comprehension needs the employment of methods before, during, and after reading.

Strategies can be defined as a purposeful activity that readers take to construct and enhance their comprehension (Jimenez, Garcia, \& Pearson, 1996; Pritchard \& O'Hara, 2008).

Therefore, a reading comprehension strategy is seen as "a psychological feature or activity action that's enacted beneath specific discourse conditions, with the goal of up some side of comprehension"(Graesser, 2007, P. 6). As people learn to read in the first language, they use particular strategies in reading for specific purposes. Once they know how to activate and effectively use a set 
of strategies, they can apply them to new texts and new tasks. This assumption is part of the studies conducted in this dis sertation.

\subsection{Research Hypothesis}

In order to probe the research questions, the following hypothesis was formulated:

H1: Scaffolding is effective for knowledge of vocabulary of Iranian EFL language learners.

\section{METHODOLOGY}

The study was an experimental, pre-posttest control group design. Students were randomly assigned to form a treatment and a control group. Using a pretest-posttest control-group design allowed the researcher to attribute posttest change in the treatment group, beyond that of the control group change, to the intervention (Gall, et al., 2007).

\subsection{Participants}

The participant population of this study was determined as the 22 EFL students in Bandar Abbas, Iran. They are both male and females.

\subsection{Procedure}

\section{Testing Procedures}

All students were tested by the researcher. Students were assessed individually during the pretest for the Peabody Picture Vocabulary Test. Students were assessed in small groups for the English Tier Two Vocabulary Assessment and the comprehension measure. After the intervention, students were assessed on the English Tier Two Vocabulary Assessment, comprehension measure, and the social validity survey.

\section{Intervention Procedures}

Students in both the treatment and control groups met with the researcher daily for the duration of the study. The students were on block scheduling and have three blocks per day. Therefore, the researcher created both a treatment and a control group for each block, making a total of six small group sessions a day. Students met with the researcher for 10-15 minutes a day and received Tier Two vocabulary instruction using either vocabulary scaffolding intervention or the comparison, definitional intervention.

\section{RESULTS}

The treatment and control groups were assessed for pretest differences on the ETTVA and comprehension assessments. A one way ANOVA revealed no significant difference between the treatment and control groups at the time of pre assessment or the ETTVA $F(1,22)=69, p=.42$. A one way ANOVA revealed no significant difference for the treatment and control groups on the comprehension measure, $F(1,22)=1.21, p=.28$. Pre and posttest means and standard deviations are reported in Table 1. A family wise alpha of .05 was used with the Bonferroni method to determine significance for all of the statistical analyses in order to control the error rate.

Table.1: Pre and Post Test Means and Standard Deviations for ETTVA and Comprehension Assessments

\begin{tabular}{lccccc}
\multicolumn{1}{c}{ TX } & \multicolumn{2}{c}{ Control } \\
\hline Pre-test & & M & SD & M & SD \\
PPVT & 158.15 & 20.30 & 157.15 & 16.66 & \\
ETTVA & 96.15 & 22.53 & 90.15 & 14.46 & \\
Comp & 38 & 22. & 46.95 & 10.56 & \\
Post-test & & & & & \\
ETTVA & 126.12 & 17.53 & 100.25 & 14.08 & \\
Comp & 54.35 & 17.96 & 52.15 & 19.06 & \\
\hline
\end{tabular}

Both the treatment and control groups were pre assessed and post assessed using the ETTVA. Scores from this assessment were analyzed using ANOVA. For vocabulary hypothesis (a), results of the ANOVA revealed that students in the vocabulary scaffolding intervention made gains on Tier Two academic vocabulary at a statistically significantly higher rate than those in the definitional control group: $F$ (1, $22)=5.701, p=.03$. The ANOVA revealed a significant difference between pretest and posttest, $F(1,22)=44.075$, $p<.000$. Finally, the ANOVA revealed a significant interaction effect, $F(1,22)=10.84, p=.003$. An effect size was also calculated for the ETTVA posttest, $d=1.59$. 
Table.2: ETTVA Item Response Percentages

\begin{tabular}{lccccc} 
& 1 & 2 & 3 & 4 & 5 \\
Pre-test & $2.31 \%$ & $29.32 \%$ & $22.13 \%$ & $6.29 \%$ & $27.72 \%$ \\
& & & & & \\
Post-test & $0.00 \%$ & $22.72 \%$ & $13.93 \%$ & $4.89 \%$ & $49.42 \%$ \\
\hline
\end{tabular}

Both the treatment and control groups were pre assessed and post assessed using the ETTVA and comprehension measure. Scores for these assessments were analyzed using ANOVA to address the hypotheses. For comprehension hypothesis, results of the ANOVA revealed that there was no group effect on comprehension: $F(1,22)=.208, p=$ .652 , observed power $=.072$. ANOVA revealed a

Table 3 significant difference between pretest and posttest, $F(1,22)$ $=7.324, p=.013$.

After students participated in the intervention, they were administered a survey to determine their feelings regarding the intervention. The results from the student responses to the post intervention survey are listed in Table 3.

Post-Intervention Affective Survey

Results

Average Rating (0-100)

71.92

$\mathbf{T}$

$\mathbf{F}$

$\begin{array}{llll}\text { n } & \% & \text { n } & \%\end{array}$

I learn a lot from this study.

I enjoyed being a part of this study.

22

21

I would participate in a study like this again.

20

$\begin{array}{ll}95.83 & 1 \\ 83.33 & 4\end{array}$

$\begin{array}{rr}0 & 0 \\ 1 & 4.16 \\ 4 & 16.67\end{array}$

The best part about the study was

Food

Small Groups

Learning

Help

The worst part about the study was

Working on PBL at the same time

Too much writing vocabulary

None

$\begin{array}{ll}13 & 62.5 \\ 3 & 12.5 \\ 6 & 25 \\ 1 & 4.17\end{array}$

62.5

12.5

4.17

$\begin{array}{ll}9 & 37.5 \\ 2 & 8.33 \\ 3 & 12.5\end{array}$

From an affective perspective, students in the study enjoyed participating. A large majority of students (100\%) in both the treatment and the control group felt they learned a lot during the study's duration. A majority of students $(95.83 \%)$ enjoyed being a part of the study, and a majority of students $(83.33 \%)$ felt they would be willing to participate in a study like this again. So, the results of this nature indicate that students were motivated to participate in both the treatment and the control conditions.

\section{DISCUSSION}

Regarding the research question, this study was an attempt to determine whether scaffolding is effective for learning students or not. It also increases the Tier Two academic vocabulary knowledge of Iranian EFL students. The researcher also hoped to increase the comprehension levels of students by providing intervention in Tier Two academic vocabulary. According to the results, students in the vocabulary scaffolding treatment group demonstrated more growth on ETTVA than those in the definitional control group. This result confirms that the use of vocabulary scaffolding increases academic vocabulary knowledge of EFL students as compared to definitional instruction. There was a significant pretest and posttest effect on Tier Two academic vocabulary knowledge for students who are EFL. Finally, was a significant interaction effect between groups and tests on Tier Two academic vocabulary knowledge? The results add to the research confirming Beck's theory of the importance of robust 
instruction of a word improving students' understandings of that word. This result also adds to the research supporting the importance of Tier Two academic vocabulary improving the depth and breadth of EL students' overall vocabulary knowledge.

This result demonstrates that robust instruction improves student knowledge of vocabulary better than simple, definitional instruction, which only provides students with one dimension of a word's meaning. This result is consistent with the results from a current metaanalysis of 37 studies considering the impact of vocabulary on comprehension (Elleman, Lindo, Morphy, \& Compton, 2009). Similarly, in this study, the focus on Tier Two academic vocabulary improved comprehension regardless of the strategy. The results from the ANCOVA reveal that previous English oral vocabulary data foreseen student'ssuccess throughout th evocabulary staging intervention. This finding supports the researcher's initial hypothesis.

\subsection{Implications of the Study}

The scaffolding intervention program is useful for teacher education or professional development programs. The intervention program provides a step by step model on how to learn to scaffold, i.e., the model of contingent teaching. This study contributed to our understanding of the circumstances in which low or high contingent support is beneficial.

\subsection{Suggestions for further research}

The first suggestion for future research in this area all stem from the limitations of the assessments used in this study. In the future, either a parallel form of the comprehension measure needs to be created, or a standardized comprehension assessment should be used to determine concurrent validity for the comprehension measure.

\section{REFERENCES}

[1] Beck, I.L. \& McKeown, M.G. (2007). Increasing young low-income children's oral vocabulary repertoires through rich and focused instruction. The Elementary School Journal, 107, 251-271.

[2] Beck, I.L., McKeown, M.G. \&Kucan, L. (2008).Creating Robust Vocabulary: Frequently Asked Questions and Extended Examples (Solving Problems in Teaching of Literacy). New York, NY: The Guilford Press.

[3] Beck, I.L., McKeown, M.G., \&Kucan, L. (2013).Bringing Words to Life, Second Edition: Robust Vocabulary Instruction. New York, NY: The Guilford Press.
[4] Beck, I.L., McKeown, M.G. \&McCaslin, E.S. (1983).Vocabulary development: Not all contexts are created equal. The Elementary School Journal, 83, 177-181.

[5] Biemiller, A. (2007). The influence of vocabulary on reading acquisition. Encyclopedia of Language and Literacy Development.

[6] Blachowicz, C.L. \& Fisher, P. (2001).Vocabulary instruction. In M.L. Kamil, P.B.M osenthal, P.D. Pearson, and R. Barr (Eds.).Handbook of Reading Research, Vol. III (pp. 503-524).Mahwah, NJ: Lawrence Erlbaum Associates, Publishers.

[7] Calderon, M., Slavin, R., \& Sanchez, M. (2011). Effective instruction for English Learners. The Future of Children, 21, 1, 103-127.

[8] Carlo, M.S., August, D., McLaughlin, B., Snow, C., Dressler, C., Lipman, D. Lively, T.J.\&White, C.E. (2004). Closing the gap: addressing the vocabulary needs of English-language learners in bilingual and mainstream classrooms. Reading Research Quarterly, 39,188-215.

[9] Carlo, M.S., August, D. \& Snow, C.E. (2005). Sustained vocabulary-learning strategy instruction for English-language learners. In Hiebert, E.H. \&Kamil, M.L. (Eds.).Teaching and Learning Vocabulary: Bringing Research to Practice. Mahwah, NJ: Lawrence Erlbaum Associates, Inc.

[10] Cisco, B.K. \&Padron, Y. (2012).Investigating vocabulary and reading strategies with middle grades English language learners: a research synthesis. Research in Middle Level Education, 36, 1-23.

[11] Echevarria, J. Vogt, M., \& Short, D.J. (2013).Making Content Comprehensible for English Learners: The SIOP Model. Boston, MA: Pearson.

[12] Graves, M.F., August, D., \&Mancilla-Martinez, J. (2013).Teaching Vocabulary to English Language Learners: Language and Literacy Series. New York, NY: Teachers College Press.

[13] Hart, B. \&Risley, T.R. (1999).Meaningful Differences in the Everyday Experiences of Young American Children. Baltimore, MD: Paul H. Brookes, Publishing Co.

[14] Hill, J.D. \& Flynn, K.(2008).Asking the right questions. Journal of Staff Development, 29, 46-52.

[15] Kelley, J.G., Lesaux, N.K., Kieffer, M.J., \& Faller, S.G. (2010).Effective academic vocabulary instruction in the urban middle school. The Reading Teacher, 64, 5-14.

[16] Kieffer, M.J. \& Lesaux, N.K.(2010). Morphing into adolescents: Active word learning for English 
language learners and their classmates in middle school. Journal of Adolescent and Adult Literacy, 54, 47-56.

[17] Kim, W. \&Linan-Thompson, S. (2013). The effects of self-regulation on science vocabulary acquisition of English Language Learners with learning difficulties. Remedial and Special Education, 34, 225-236.

[18] Lara-Alecio, R., Tong, F., Irby, B.J., Guerrero, C., Huerta, M. \& Fan, Y. (2012). The effect of an instructional intervention on middle school English Learners' science and English reading achievement. Journal of Research and Science Technology, 49, 9871011.

[19] Lee, S.H. \& Muncie, J. (2006). From receptive to productive: Improving ESL learner's use of vocabulary in a postreading composition task. Teachers of English to Speakers of Other Languages, 40, 295-320.

[20] Rivera, C.J., Wood, C.L., \& Spooner, F. (2012). Comparative effects of Spanish and English vocabulary instruction for English Language Learners with moderate intellectual disability. Multiple Voices for Ethnically Diverse Exceptional Learners, 13, 4255.

[21] Short, D.J., Fidelman, C.G., \& Louguit, M. (2012). Developing academic language in English Language Learners through sheltered instruction. TESOL Quarterly, 46, 334-361.

[22] Silverman, R. \& Hines, S. (2009). The effects of multimedia-enhanced instruction on the vocabulary of English-language-learners and non-English-languagelearners in pre-kindergarten through second grade. Journal of Educational Psychology, 101, 305-314.

[23] Smith, N.B. (2002). Chapter Five The period of emphasis upon reading as a cultural asset. American Reading Instruction. International Reading Association.

[24] Smith, N.B. (2002). Chapter Nine: The Period of Expanding Knowledge and Technological Revolution. American Reading Instruction. International Reading Association.

[25] Soltani, R. (2011). Extensive reading: A stimulant to improve vocabulary knowledge. Studies in Literature and Language, 2, 161-167.

[26] Spycher, P. (2009). Learning academic language through science in two linguistically diverse Kindergarten classes. The Elementary School Journal, 109, 359-379.
[27] Stahl, S.A. \& Fairbanks, M. M. (1986). The effects of vocabulary instruction: A model- based meta-analysis. Review of Educational Research, 56, 72-110.

[28] Taboada, A. \& Rutherford, V. (2011). Developing reading comprehension and academic vocabulary for English language learners through science content: a formative experiment. Reading Psychology, 32, 113157.

[29] Townsend, D. \& Collins, P. (2009). Academic vocabulary instruction and middle school English learners: an intervention study. Read Writ, 22, 9931019. U.S. Department of Education, Institute of Education Sciences: National Assessment of Educational Progress, National Center for Education Statistics. (2005). The nation's report card, reading. Washington, DC.

[30] Vadasy, P.F., Nelson, R., \& Sanders, E.A. (2011). Longer term effects of a Tier 2 vocabulary intervention for English Learners. Remedial and Special Education, 34, 91-101.

[31] Vaughn, S, Martinez, L.R., Reutebuch, C.K., Carlson, C.D., Thompson, S.L., \& Francis, D.J. (2010). Enhancing social studies vocabulary and comprehension for 7th grade English language learners: findings from two experimental studies. (SREE Conference Abstract).

[32] Wiley, T.G. \& de Klerk, G. (2010). Common myths and stereotypes regarding literacy and language diversity in the multilingual United States. Ethnolinguistic Diversity and Education. New York: Routledge.

[33] Yoon, B. (2007). Offering of limiting opportunities: Teachers' roles and approaches to English-Language Learners' participation in literacy activities. The Reading Teacher, 61, 216-255. 